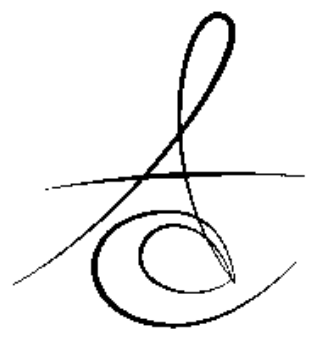

\title{
DEĞİşİK YÖNTEMLERLE HAZIRLANAN METAL ALT YAPILAR ÜZERİNDEKİ VENEER PORSELENLERİNİN KIRILMA DİRENCİNE FARKLI ALT YAPI ŞEKİLLERİNİN ETKİSİNİN İNCELENMESİ ${ }^{*}$
}

\section{AN ANALYSIS OVER THE EFFECT OF COPING DESIGN ON THE FRACTURE RESISTANCE OF VENEER PORCELAINS APPLIED ON METAL FRAMEWORKS PREPARED THROUGH VARIOUS METHODS ${ }^{\neq}$}

Prof. Dr. Zeynep YEŞíL DUYMUŞ*

Yrd. Doç. Dr. Murat ALKURT*

\begin{abstract}
Makale Kodu/Article code: 2717
Makale Gönderilme tarihi; 26.03.2016

Kabul Tarihi: 17.06 .2016
\end{abstract}

öz

Amaç: Bu çalışmada, değişik yöntemlerle hazırlanan metal alt yapılar üzerindeki veneer porselenlerinin kırılma direnci üzerine farklı alt yapı şekillerinin etkisi incelenmiştir.

Materyal ve Metod: Chamfer bitim hatlı olarak kesilmiş üst 1 . küçük azı dişini temsil eden metal güdükler anatomik oklüzal yüzeyli ve düz oklüzal yüzeyli olarak iki değişik şekilde CNC torna tezgahında hazırlanmış, alınan ölçülerden 30 adet epoksi rezin güdük elde edilmiştir. Farklı yöntemlerle elde edilen metal alt yapılar üzerine üst yapı porseleni uygulanarak kuronlar hazırlanmıştır. Epoksi rezin güdükler kuronlar üzerine simante edilmiş ve veneer porselenlerinin kırılma dirençleri Universal test cihazında değerlendirilmiştir.

Bulgular: Kırılma direnci değerleri üzerine alt yapı şekli ve hazırlama yöntemlerinin etkisinin anlamlı olduğu varyans analizi ile saptanmıştır $(p<0.05)$.

Sonuç: Çalışmada anatomik alt yapılar üzerinde freze tekniğiyle hazırlanan veneer seramiklerinde en yüksek kırılma direnci değerleri tespit edilmiştir.

Anahtar Kelimeler: Metal alt yapılar, alt yapı şekli, kırılma direnci.

\section{GİRİŞ}

Diş eksikliklerinin giderilmesinde metal altyapılı seramik restorasyonlar 1950 'lerin ortalarından bu yana sabit protetik tedavilerde kullanılmaktadır. ${ }^{1}$ Bu süre içerisinde seramik ve altyapı materyallerinin hem içeriklerinde, hem de fiziksel özelliklerinde elde edilen
ABSTRACT

Aim: In this study, the effect of different metal framework methods and coping design on the fracture resistance of veneer porcelains.

Materials and Methods: Two different metal dies having anatomic and smooth occlusal surface designs were manufactured using CNC machine to simulate prepared upper first premolar tooth with chamfer finish line, impressions were taken and 30 epoxy resin dies were produced subsequently. Veneering ceramics were applied on metal frameworks which were produced by different methods and crowns were finished. Crowns were cemented on to the epoxy resin dies and fracture strength of veneering ceramics were evaluated using Universal Testing Machine.

Results: Variance analyses demonstrated that framework design and manufacturing methods had a significant effect on fracture strength of tested specimens $(p<0.05)$.

Conclusion: In this study, veneering ceramics which were applied on anatomically shaped milled frameworks showed the highest fracture strength values.

Key Words: Metal frameworks, coping design, fracture resistance.

gelişmelere karşın oklüzal kuvvetler, yorulma, travma, mikrodefektler veya uygun olmayan tasarım gibi etkenler sonucunda metal-porselen restorasyonlarda kırılma olabilmektedir. ${ }^{2,3}$

Döküm işlemi metal alt yapıların hazırlanması için en fazla kullanılan yöntemdir. ${ }^{2}$ Ayrıca metal alaşımlarından hazırlanan bloklardan CAD-CAM (Com-

*Recep Tayyip Erdoğan Üniversitesi, Diş Hekimliği Fakültesi, Protetik Diş Tedavisi AD

₹ 5.Uluslararası Türk Prostodonti ve İmplantoloji Derneği Bilimsel Sempozyumunda poster

(Poster No:201622) olarak sunulmuştur. 18-20 Mart 2016, Erzurum 
puter Aided Design-Computer Aided Manufacturing) yöntemiyle ve lazer sinterleme (DLMS) tekniğiyle metal alt yapılar elde edilebilmektedir. ${ }^{4}$ Döküm tekniği ile karşılaştıııldığında CAD-CAM kullanımının üretim aşamalarını daha basit bir hale dönüştürerek zaman ve maliyet avantajı sağladığı görülmektedir. ${ }^{5,6}$

Metal-porselen restorasyonlarda üst yapı porseleninin alt yapıya bağlantısı farklı iki özellikte ve yapıda materyaller olduklarından oldukça önem taşımaktadır. ${ }^{7}$ Kalıcı bir bağlantı için bazı özelliklerin birbirlerine uygun olması gerekmektedir. ${ }^{8}$

Veneer porselenindeki minör kırıklar ve veneer porseleninin alt yapıdan ayrıması, metal alt yapılı restorasyonlarda en sık karşılaşılan başarııızlıklardır. ${ }^{9,10}$

Metal alt yapıların farklı şekillerde tasarlanmasıyla veneer porseleninin kırıma direncinin arttığı gözlemlenmiştir. ${ }^{4}$ Bu çalışma, değişik yöntemlerle hazırlanan metal alt yapılar üzerindeki veneer porselenlerinin kırıma dirençlerine farklı alt yapıların (anatomik ve anatomik olmayan) etkisini incelemek amacıyla yapılmıştır.

Çalışmanın hipotezi, farklı hazırlama yöntemlerinin ve alt yapı şekillerinin veneer porselenlerinin kırılma direncini etkileyeceği yönündedir.

\section{MATERYAL ve METOD \\ Örneklerin Hazırlanması:}

CNC torna tezgahında (Space Turn LB2000, Okuma Corp, Japonya) örneklerin elde edileceği kesilmiş üst 1. küçük azı dişini temsil eden güdükler 6 $\mathrm{mm}$ kuron boyunda ve $6^{\circ}$ taper açısında chamfer bitim hatlı olarak; 1. Güdük; anatomik oklüzal yüzeyli, 2. Güdük; düz oklüzal (anatomik olmayan) yüzeyli olarak hazırlanmıştır (Resim 1,2).

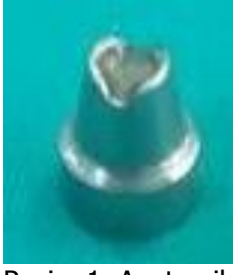

Resim 1. Anatomik Oklüzal Yüzeyli Güdük

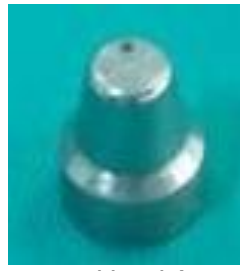

Resim 2. Düz Oklüzal (Anatomik Olmayan) Yüzeyli Güdük
Güdüklerden silikon esaslı ölçü maddesi (Speedex, Coltène/Whaledent AG, Langenau, Almanya) kullanılarak çift karıştırma tekniği ile alınan ölçülerden 15 adet anatomik, 15 adette anatomik olmayan epoksi rezin güdük elde edilmiş, daha sonra alt yapıların hazırlanma işlemine geçilmiştir.

Çalışmada Tablo 1'de gösterilen alt yapı materyalleri kullanılmıştır.

Konvansiyonel Döküm Yoluyla Elde Edilen Metal Alt Yapıların Hazırlanması:

Kayıp mum tekniği ile hazırlanacak olan metal alt yapıların döküm işlemlerinde kullanılan anatomik ve anatomik olmayan oklüzal yüzeyli alt yapılar dizayn programı (DWOS yazılım, Dental Wings Inc, Montreal, Kanada) ile tasarlanarak polimetil metakrilat bloktan freze makinesi (Yenadent D-40, Yenadent, İstanbul, Türkiye) ile hazırlanmıştır.

Tablo 1. Kullanılan Materyaller ve Hazırlama Yöntemleri

\begin{tabular}{|c|c|c|c|}
\hline Grup & Yöntem & Materyal & Üretici Firma \\
\hline $\begin{array}{l}\text { Döküm } \\
\text { Metal }\end{array}$ & $\begin{array}{l}\text { Konvansiyonel } \\
\text { Metal Alt Yapı }\end{array}$ & $\mathrm{Co}-\mathrm{Cr}$ & $\begin{array}{l}\text { Wirobond@C, } \\
\text { Bego Dental, } \\
\text { Bremen, Almanya }\end{array}$ \\
\hline $\begin{array}{l}\text { Freze } \\
\text { Metal }\end{array}$ & $\begin{array}{l}\text { CAD-CAM } \\
\text { Sistem }\end{array}$ & $\begin{array}{l}\text { Co-Cr } \\
\text { Metal } \\
\text { Blok }\end{array}$ & $\begin{array}{l}\text { Yenadent, } \\
\text { İstanbul, Türkiye }\end{array}$ \\
\hline $\begin{array}{l}\text { DLMS } \\
\text { Metal }\end{array}$ & $\begin{array}{l}\text { CAD-CAM } \\
\text { Sistem }\end{array}$ & $\begin{array}{l}\text { Co-Cr Toz } \\
\text { Metal }\end{array}$ & $\begin{array}{l}\text { Concept Laser } \\
\text { Gmbh, } \\
\text { Lichtenfels, } \\
\text { Almanya }\end{array}$ \\
\hline
\end{tabular}

CAD-CAM yoluyla üretilen rezin esaslı alt yapılar üretici firmanın önerileri doğrultusunda hazırlanan fosfat bağlantılı revetmana (Bellavest $T$, Bego, Almanya) alınmış ve indüksiyon döküm makinesinde (Mikrotek Inf-2010, Mikrotek Dental, Ankara, Türkiye) Co-Cr metal alaşımı (Wirobond $\AA$ C, Bego Dental, Bremen, Almanya) kullanılarak metal alt yapılar elde edilmiştir. Revetman artıkları 50 mikrometre'lik alüminyum oksit partikülleri (Korox 50, Bego, Almanya) ile kumlanarak temizlenmiştir. Örneklerin kalınlıkları kontrol edilmiş uygun olmayanların yerlerine yeni dökümler yapılmıştır.

Freze Tekniği ile Üretilen Co-Cr Metal Alt Yapıların Hazırlanması:

Önceden hazırlanmış olan modeller üç boyutlu optik tarayıcı (Dental Wings Inc, Montreal, Kanada) ile bilgisayar ortamına aktarılmıştır. Dijital model üzerinde anatomik ve anatomik olmayan oklüzal yüzeyli metal alt yapılar dizayn programı (DWOS yazılım, Dental Wings Inc, Montreal, Kanada) yardımı ile tasarlanmıştır. Metal alt yapılar Co-Cr esaslı metal bloktan (Yenadent, İstanbul, Türkiye) freze makinesi (Yenadent D40, Yenadent, İstanbul, Türkiye) ile hazırlanmış ve kalınlıkları kontrol edilmiştir.

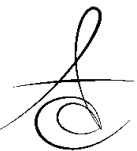


Atatürk Üniv. Diş Hek. Fak. Derg.

J Dent Fac Atatürk Uni

Cilt:26, Sayı:3, Yıl: 2016, Sayfa: 457-464

Direkt Lazer Metal Sinterizasyonu (DLMS) Yoluyla Elde Edilen Co-Cr Metal Alt Yapıların Hazırlanması:

Önceden hazırlanmış olan modeller lazer tarayıcı (Openscan 100, Laserdenta GmbH, Bergheim, Almanya) ile taranarak veriler bilgisayar ortamına aktarılmıştır. Anatomik ve anatomik olmayan oklüzal formdaki alt yapıların tasarım işlemi; dizayn programı (DWOS yazılım, Dental Wings Inc, Montreal, Kanada) yardımı ile diğer metal alt yapıların tasarımında kullanılan verilere bağlı kalınarak yapıldıktan sonra alt yapılar hazırlanmıştır. Alt yapıların kalınlıkları tek tek kumpasla kontrol edilmiş, standartlara uymayan örneklerin yerlerine yenileri yapılmıştır.

\section{Alt Yapılara Porselen Uygulanması:}

Alt yapılar tamamlandıktan sonra üst yapı porselenlerinin hazırlanma işlemine geçilmiştir. Standardizasyonun sağlanabilmesi için anatomik ve düz oklüzal yüzeyli birer alt yapı üzerine üst 1 . küçük azı dişinin anatomik özelliklerini yansıtan akrilikten kuron hazırlandıktan sonra, alt yapı-akrilik rezin restorasyonların silikon esaslı ölçü maddesi ile ölçüleri alınmıştır. Elde edilen ölçü bistürü ile bukko-lingual yönde ortadan ikiye ayrılmış ve indeks olarak kullanılmıştır.

\section{Metal Alt Yapılara Porselen Uygulanması}

Metal alt yapılara Vita VM9 (Vident/Vita, Brea, CA) porseleni imalatçı firmanın önerileri doğrultusunda aşağıdaki aşamalar takip edilerek uygulanmıştır.

1- Bağlanma Tabakasının Uygulanması:

Metal alt yapılara ön kurutma işlemi $500^{\circ} \mathrm{C}$ ' de 6 dakika uygulanmış, daha sonra vakum altında dakikada $80^{\circ} \mathrm{C}$ artacak şekilde $980^{\circ} \mathrm{C}^{\prime}$ ye kadar fırın ısıtılmıştır. Vakum kapatılmış 2 dakika beklenmiş ve fırının kapağı açılarak soğutma işlemi gerçekleştirilmiştir.

2- İlk Opak Tabakasının Uygulanması:

Alt yapılara opak sürülmüş ön kurutma işlemi $500^{\circ} \mathrm{C}$ de 6 dakikada yapılmış, daha sonra vakum altında dakikada $55^{\circ} \mathrm{C}$ artacak şekilde $960^{\circ} \mathrm{C}^{\prime}$ ye kadar fırın ısıtılmıştır. Vakum kapatıımış 1 dakika beklenmiş ve fırının kapağı açılarak soğutma işlemi gerçekleştirilmiştir.

3- İkinci Opak Tabakasının Uygulanması:

Alt yapılara ikinci opak tabakası sürülmüş ön kurutma işlemi $500^{\circ} \mathrm{C}$ de 6 dakika yapılmış, daha sonra vakum altında dakikada $55^{\circ} \mathrm{C}$ artacak şekilde $930^{\circ} \mathrm{C}^{\prime}$ ye kadar fııın ısıtılmıştır. Vakum kapatılıp 1 dakika beklendikten sonra, fırının kapağı açılarak soğutma işlemi gerçekleştirilmiştir.
YEŞIL DUYMUŞ,

ALKURT

\section{4- Birinci Tabaka Dentin Uygulanması:}

Örneklere dentin uygulanmış, ön kurutma işlemi $500^{\circ} \mathrm{C}^{\prime}$ de 6 dakikada yapılmış ve vakum altında dakikada $55^{\circ} \mathrm{C}$ artacak şekilde $910^{\circ} \mathrm{C}$ kadar fırın ısıtılmıştır. Vakum kapatılarak 1 dakika beklendikten sonra fırının kapağı açılarak soğutma işlemi gerçekleştirilmiştir.

5- İkinci Tabaka Dentin Uygulanması:

İkinci tabaka dentin uygulanmış ve ön kurutma işlemi $500^{\circ} \mathrm{C}^{\prime}$ de 6 dakikada yapılmış sonra vakum altında dakikada $55^{\circ} \mathrm{C}$ artacak şekilde $910^{\circ} \mathrm{C}$ kadar fırın ısıtılmış, vakum kapatılmış 1 dakika beklenmiş ve fırının kapağı açılarak soğutma işlemi gerçekleştirilmiştir.

6- Glaze İşlemi:

Glaze uygulanmış örneklere $500^{\circ} \mathrm{C}^{\prime}$ de 5 dakika ön kurutma işlemi uygulanmış, vakum uygulanmadan dakikada $80^{\circ} \mathrm{C}$ artacak şekilde $900^{\circ} \mathrm{C}$ kadar fırın ısıtılmış 1 dakika beklendikten sonra fırının kapağı açılarak soğutma işlemi gerçekleştirilmiştir. Alt yapılara veneer porseleni uygulandıktan sonra, örneklerin epoksi rezin güdükler üzerine simantasyon işlemine geçilmiştir.

\section{Örneklerin Simantasyonu}

50 mikrometre boyutundaki alüminyum oksit partikülleri (Danville Engineering Inc, Danville, Calif) ile kumlanan örnekler, rezin siman (Panavia F 2.0, Kuraray Dental, Japan) ile üreticinin önerdiği şekilde epoksi rezin güdüklere simante edilmiş ve 50 Newtonluk kuvvet 10 dakika boyunca tatbik edilmiştir. Örneklerin yüzeylerine halojen ışık cihazı (Hilux Ultraplus, Benlioğlu Dental, İstanbul) ile 3 saniye ışık verildikten sonra artık simanlar dikkatli bir şekilde temizlenmiş ve bütün yüzeylere 20 saniye ışık verilerek polimerizasyon işlemi tamamlanmıştır. Daha sonra üretici firmanın önerileri doğrultusunda örneklerin kenar kısımlarına 3 dakika süre ile Oxyguard (Oxyguard II, Kuraray Dental, Japan) tatbik edilmiştir. Örnekler $37^{\circ} \mathrm{C}$ distile suda 48 saat süre ile bekletilmiş daha sonra kırılma direnci testi uygulanmıştır.

\section{Kırılma Direnci Testi}

Test Atatürk Üniversitesi Diş Hekimliği Fakültesi, Protetik Diş Tedavisi Anabilim Dalında bulunan Instron Universal (Instron Corp, USA) test cihazı kullanılarak gerçekleştirilmiştir. Kuvvet uygulaması sırasında dik açıda hareketsiz kalması için örnekler, Instron aletinin alt parçasına yerleştirilen düzenek ile sabitlenmiştir. Cihazın hareketli olan üst parçasına ise ucunda $5 \mathrm{~mm}$ çapında çelik bilye bulunan bir kuvvet 
uygulayıcı uç yerleştirilmiştir. Örneklerin oklüzal yüzeylerinin tam orta noktasından ilk kırılma oluşuncaya kadar $0.5 \mathrm{~mm} /$ dakika başlık hızı ile kuvvet uygulanmıştır. Kırılma kuvvetleri Newton (N) cinsinden kaydedilmiştir.

\section{Kopma Şekillerinin İncelenmesi}

Tüm örneklerin kuvvet uygulama sonrasında kopma şekilleri, Atatürk Üniversitesi Diş Hekimliği Fakültesi Pedodonti Anabilim Dalı araştırma laboratuvarında bulunan optik mikroskopta (Novex RZ-Range, Novex Inc., Amhem, Hollanda) incelenmiştir. Kopma şekilleri; adeziv (veneer porseleninin alt yapıdan tamamen ayrıldığı), koheziv (veneer porseleninin tamamen kendi içinde kırıldığ) ve kombine (adeziv+koheziv) kopma olmak üzere 3 gruba ayrilarak incelenmiştir.

\section{Verilerin}

\section{Değerlendirilmesi}

\section{İstatistiksel}

Olarak

Elde edilen veriler, SPSS 16 programı kullanılarak iki yönlü varyans analizi, çoklu karşılaştırmalar için Tukey HSD ve ikili karşılaştırmalar için t-testi kullanılarak istatistiksel olarak değerlendirilmiştir.

\section{BULGULAR}

\section{Kırılma Dirençlerinin Değerlendirilmesi}

Elde edilen verilerin değerlendirilmesi amacıyla 2-Yönlü varyans analizi kullanılmıştır. Varyans analiz tablosu incelendiğinde; kırıma direnci değerlerine alt yapı şekli ve hazırlama yöntemlerinin etkisinin anlamlı olduğu istatistiksel olarak tespit edilmiştir $(p<0.05)$.

Elde edilen verilerin ortalama ve standart sapma sonuçları Tablo 2'de gösterilmiştir. En yüksek veneer porselen kırılma direnci değerlerinin (1722.80 $\mathrm{N})$ anatomik alt yapılar üzerinde freze tekniğiyle hazırlanan veneer kuronlarda, en düşük kırılma direnci değerlerinin $(1380.00 \mathrm{~N})$ ise anatomik olmayan alt yapılar üzerinde direkt lazer metal sinterizasyonu (DLMS) ile elde edilen kuronlarda olduğu görülmüştür. Alt yapı şekline göre veneer porselenlerinin kırıma dirençleri incelendiğinde; anatomik alt yapılar üzerinde hazırlanan örneklerde (1590.27 N), anatomik olmayan alt yapılar üzerinde hazırlanan örneklerden (1493.13 N) daha yüksek kırıma direnci değerleri tespit edilmiştir (Tablo 2). Hazırlama tekniklerine göre değerlendirildiğinde; en yüksek (1560.75 N) kırılma direnci değerleri freze tekniği ile hazırlanan kuronlarda, en düşük $(1274.85 \mathrm{~N})$ kırılma direnci değerleri DLMS yöntemi ile hazırlanan kuronlarda saptanmıştır (Tablo 3, Grafik 1).
Yapılan t-testi sonuçlarına göre; anatomik ve anatomik olmayan alt yapılar üzerinde hazırlanan veneer kuronların kırılma dirençleri arasındaki farkın istatistiksel olarak anlamlı olduğu görülmüştür $(p<0.05)$.

Döküm ve freze yöntemiyle elde edilen kuronlardaki veneer porselenlerin kırıma direnci arasındaki farkın anlamlı ( $p>0.05)$ olmadığı, bu iki grubun DLMS grubundan farkının ise anlamlı $(p<0.01)$ olduğu Tukey HSD testi ile tespit edilmiştir (Tablo 3).

Tablo 2. Kırıma Direnç Değerlerinin Dağılımları $(N=5)$

\begin{tabular}{|c|c|c|c|}
\hline Grup & Alt Yapı Şekli & $\begin{array}{l}\text { Ortalama } \\
\text { (N) }\end{array}$ & $\begin{array}{l}\text { Standart } \\
\text { Sapma }\end{array}$ \\
\hline \multirow{3}{*}{$\begin{array}{l}\text { Döküm } \\
\text { Metal }\end{array}$} & Anatomik & 1616.00 & 68.78 \\
\hline & Anatomik & 1622.00 & 67.60 \\
\hline & Olmayan & & \\
\hline \multirow{3}{*}{$\begin{array}{l}\text { Freze } \\
\text { Metal } \\
\end{array}$} & Anatomik & 1722.80 & 24.07 \\
\hline & Anatomik & 1477.40 & 39.61 \\
\hline & Olmayan & & \\
\hline \multirow{6}{*}{$\begin{array}{l}\text { DLMS } \\
\text { Metal }\end{array}$} & Anatomik & 1432.00 & 76.62 \\
\hline & Anatomik & 1380.00 & 77.46 \\
\hline & Olmayan & & \\
\hline & Anatomik & 1590.27 & 66.61 \\
\hline & Anatomik & 1493.13 & 67.46 \\
\hline & Olmayan & & \\
\hline
\end{tabular}

Tablo 3. Materyallerin Kırılma Direnç Değerlerinin Tukey HSD Testi Sonuçları

\begin{tabular}{llll}
\hline Yöntem & $\mathrm{N}$ & 1 & 2 \\
\hline Döküm Tekniği & 10 & $1494.05 \mathrm{~N}$ & \\
Freze Tekniği & 10 & $1560.75 \mathrm{~N}$ & \\
DLMS Tekniği & 10 & & $1274.85 \mathrm{~N}$
\end{tabular}

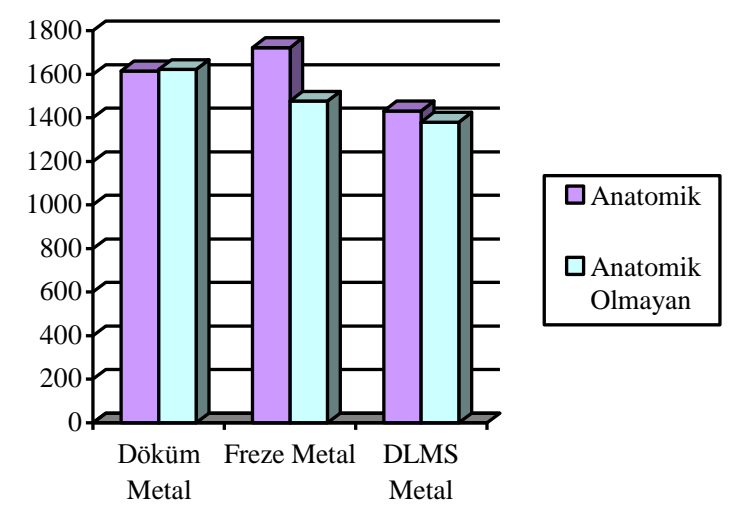

Grafik 1. Alt yapı şekillerinin kırılma direnç değerlerinin karşılaştırılması. 


\section{Kopma Şekillerinin Değerlendirilmesi}

Kopma şekilleri optik mikroskop altında değerlendirilmiştir. Döküm yöntemiyle elde edilen örneklerde $\% 50$ oranında adeziv, \%50 oranında kombine kopma, freze yöntemiyle hazırlananlarda $\% 60$ oranında adeziv, $\% 40$ oranında kombine kopma, DLMS yöntemiyle hazırlananlarda ise \%55 oranında adeziv, \%45 oranında kombine kopma şekli görülmüştür.

\section{TARTIŞMA}

Kırıma direnci değerlerine alt yapı şekli ve hazırlama yöntemlerinin etkisinin anlamlı olduğu tespit edildiğinden çalışmanın hipotezi kabul edilmiştir.

Restorasyonların başarısını diş preparasyonlarının şekli önemli oranda etkilemektedir. Literatürlerde farklı restoratif materyallerin kırıma direnci ile ilgili çalışmalar mevcutken, değişik şekilde hazırlanan metal alt yapılı restorasyonların klinik başarısında önemli faktörler olan morfoloji dikkate alınarak yapılan kesim (anatomik) ile oklüzal yüzeyi düz (anatomik olmayan) kesilen dişler üzerinde hazırlanan restorasyonlardaki veneer porselenlerinin kırıma direnci ile ilgili çalışmaların azı̆̆ı dikkat çekmektedir. Yapılan çalışma ile bu konuda katkı sağlanılması düşünülmüştür.

Kırıma direnci değerlendirilirken farklı güdük materyalleri kullanılmaktadır. ${ }^{11-16}$ Bu çalışmada standardizasyonun sağlanabilmesi için diş morfolojisine uygun olacak şekilde (anatomik) ve düz oklüzal (anatomik olmayan) yüzeyli prepare edilmiş üst premolar dişi temsil edecek şekilde CNC torna tezgahında hazırlanan paslanmaz çelik alaşımından güdükler kullanımıştır. Güdükler, temel preparasyon prensipleri ${ }^{17}$ takip edilerek, $6^{\circ}$ taper açısı ile chamfer kenar bitim şeklinde hazırlanmıştır.

Çalışmada örnekler silikon esaslı ölçü maddeleri ile iki aşamalı ölçü tekniği ${ }^{18,19}$ kullanılarak alınan ölçülerden elde edilen, dentin ile benzer stres ${ }^{19}$ dağıımı gösterdiği belirtilen epoksi rezin güdükler üzerinde hazırlanmış ve test edilmiştir.

Mevcut oklüzal boşluğa ve restorasyonların anatomik boyutuna bağlı olarak alt yapılar üzerine uygulanan veneer porselenlerinin kalınlıkları değişebilmektedir. ${ }^{20}$ Veneer porselenlerinin hazırlanması sırasında akrilik rezin, ${ }^{11,12}$ pirinç, silikon ${ }^{21}$ gibi değişik kalıplar kullanılarak standardizasyon sağlanmaya çalışılmaktadır. ${ }^{21,22}$ Tinschert ve arkadaşları $^{23}$ ise dijital mikrometre kullanmışlardır. Bu çalışmada Vita VM9 veneer porseleni silikon kalıplar ile uygulanmış ve kalınlıklar değişik kısımlarından kumpasla ölçülmüştür.

Çalışmada, doğru sonuçlar ${ }^{24}$ elde edebilmek için bütün işlemler üretici firmaların önerileri doğrultusunda yapılmıştır.

Araştırıcılar tarafından siman aralığının, 20-40 mikron arasında olması gerektiğ $1^{17,25}$ ifade edildiğinden, bu çalışmada dizayn programları üzerinden 30 mikron kalınlığında siman aralığı ayarlanmışıı.

Metal-seramik restorasyonlar geleneksel yöntemlerle ${ }^{26}$ yada adeziv sistemlerle simante edilebilir. ${ }^{27}$ Çalışmada kuronlar yerleştirildikten sonra taşan siman temizlenmiş hava ile temasını bloke eden ajan ${ }^{28}$ marjinal bölgeye hızı bir şekilde uygulanmış ve polimerizasyon LED (Light Emitting Diode) ışık kaynağı ile yapıImıştır.

Metal destekli porselen restorasyonlarda bağlantı kuvvetini ölçmek için; makaslama, eğme, bükme, gerilme, gerilme-makaslama ve çekme testleri olmak üzere birçok test yöntemi kullanılmasına karşın, metalporselen ara yüzeyinde oluşan bağlantı kesin olarak saptanamamaktadır. Bunun temel sebebi, klinik koşulları yansıtan test standardizasyonunun sağlanamamasıdır. ${ }^{29}$ İn-vitro testlerde uygulanan insizal ve oklüzal yükleme ile kırık oluşumu ve çeşitli restorasyon sistemlerindeki direnç değerlendirilebilmektedir. Çiğneme kuvvetleri genellikle baskı şeklinde oluştuğu için çiğneme işlemi sırasında restorasyonların göstermiş olduğu dayanıklıı̆ının saptanması önemlidir. ${ }^{30}$ Ağız ortamında çeşitli kuvvetlerle karşılaşacak olan bir materyalin dayanıklı̆ı̆ının tespit edilebilmesi için en iyi yöntemin, restorasyonun anatomik formunda hazırlandıktan sonra ağızın taklit edildiği bir ortamda test edilmesinin olduğu belirtilmiştir. ${ }^{31} \mathrm{Bu}$ çalışmada, üst birinci küçük azı formunda hazırlanan örneklere oklüzal yükleme uygulanmıştır.

Yükleme hızı kırılgan materyallerin dayanıklılıklarını saptayabilmek için önemlidir $32-34$ ve düşük yükleme hızı tercih edilmektedir. ${ }^{32,35-37}$ Kırılgan materyaller için yükleme hızı International Organization for Standardization (ISO) da $1 \pm 0.5 \mathrm{~mm} /$ dakika olarak önerilmiştir. ${ }^{38}$ Çalışmada yükleme hızı $0.5 \mathrm{~mm} /$ dakika olarak uygulanmışıı. Yük uygulamak için kullanılan ucun boyutları da önemlidir. ${ }^{13}$ Çalışmalarda kullanılan kıııcı uç çapları farkılık (2.65-6.35 mm) göstermektedir. Bu araştırmada ucunda $3.5 \mathrm{~mm}$ çapında çelik top olan bir aparey ile örneklere kuvvet uygulanmıştır. 
Atatürk Üniv. Diş Hek. Fak. Derg.

J Dent Fac Atatürk Uni

Cilt:26, Sayı:3, Yıl: 2016, Sayfa: 457-464

Laboratuvarda yapılan kırılma testlerinde restorasyonların yüksek kırılma direncine sahip olduğu bilinmektedir. Bu testlerde, materyalin zarar gördüğü ilk değer belirlenmelidir. Bu noktanın üzerinde aşırı yükleme yapılması kırılmanın meydana geldiği yük değerinin yanıltıcı olmasına neden olmaktadır. Bu tip büyük kuvvetler, normal çiğneme siklusunde meydana gelmemesine rağmen, intraoral olarak restorasyonlarda kırıklar oluşmaktadır. 39

Anatomik şekilde desteklenerek hazırlanan restorasyonlarda oral fonksiyonlar ve ısırma işlemleri sırasında yükleme ve gerilme kuvvetlerinde azalma olduğu belirtilmiştir. ${ }^{40}$ Bonfante ve arkadaşları, ${ }^{4}$ alt yapıları anatomik şekilde hazırlanan restorasyonlarla anatomik olarak desteklenmeyen restorasyonları sonlu elemanlar yöntemiyle karşılaştırmışlar, anatomik olarak hazırlanan yapıların daha yüksek stres dayanımı gösterdiklerini tespit etmişlerdir. Rosentritt ve arkadaş$\mid a r{ }^{41}$ alt yapıların anatomik şekilde tüberkül formunda hazırlandıktan sonra venere edilmesi durumunda porselen tabakasına yeterli desteklik sağlanacağını belirtmişlerdir. Molin ve Karlsson ${ }^{42}$ yaptıkları çalışma sonucunda alt yapıların tam anatomik şekilde hazırlanmasının veneer seramikleri güçlendirdiğini saptamışlardır.

Arka bölgede hazırlanan metal destekli porselen kuron ve köprü protezlerinde endikasyon ve preparasyon yanılgılarından dolayı kırılmalar olabildiği gibi uniform şekilde hazırlanan metal destekler ve bunlar üzerine pişirilen değişik kalınlıktaki porselen tabakaları kırımaya neden olabilmektedir. Belirli bir kalınlığın üzerine çıkan porselen tabakaları da çiğneme basınçlarına karşı dayanıksızdır. ${ }^{43}$ Alt yapısı düz olan restorasyonlara tüberkül formu verildiğinde porselen tabakasının kalın olmasına bağı olarak kırılma direnci azaldığından, bu çalışmada da anatomik alt yapılar üzerinde hazırlanan veneer porselenlerinin, anatomik olmayan alt yapılar üzerinde hazırlananlardan daha yüksek kırılma direnci değerleri gösterdiği görülmüştür.

Günümüzde döküm metal alt yapılar hazırlanırken konvansiyonel yöntemlerle birlikte yeni teknikler kullanılmaktadır. ${ }^{44,45} \mathrm{Bu}$ çalışmada CAD-CAM yoluyla elde edilen polimetil metakrilat esaslı rezin örnekler döküm işlemlerinde kullanılmıştır.

Freze ve DLMS yöntemi ile döküm işlemlerinde oluşabilecek olumsuzluklar ortadan kaldırılmakta ve hızlı bir şekilde hastaya özel restorasyonlar hazırlanmaktadır. ${ }^{46}$
YEŞİL DUYMUŞ, ALKURT

Literatürlerde freze yoluyla elde edilen metal ve DLMS metal alt yapılar ile ilgili fazla bilgi bulunmamaktadır. Akova ve arkadaşları ${ }^{47}$ yaptıkları çalışmada döküm ( $\mathrm{Ni}-\mathrm{Cr}$ ve $\mathrm{Co}-\mathrm{Cr}$ ) ve lazer sinterleme ( $\mathrm{Co}-\mathrm{Cr}$ ) ile hazırlanan metal alt yapılara uygulanan porselenlerin bağlanma direncini karşılaştırmışlardır. En yüksek porselen bağlanma dayanıklılığını döküm $\mathrm{Ni}-\mathrm{Cr}$ alt yapılarda, en düşük porselen bağlanma dayanıklıığını ise lazer sinterleme ile hazırlanan $\mathrm{Co}-\mathrm{Cr}$ alt yapılarda saptamış olmalarına karşın, farkın istatistiksel olarak anlamlı olmadığı belirtmişlerdir.

Suleiman ve Vult von Steyern ${ }^{48}$ döküm, freze ve lazer sinterleme yöntemiyle hazırladıkları $\mathrm{Co}-\mathrm{Cr}$ alt yapılar ile döküm yoluyla elde edilen altın alt yapılara uygulanan porselenlerin kırılma dirençlerini değerlendirmişlerdir. Freze yöntemiyle elde edilen $\mathrm{Co}-\mathrm{Cr}$ alt yapılarda en yüksek kırılma dayanıkılığını, lazer sinterleme yöntemiyle hazırlanan örneklerde ise en düşük kırılma dayanıkııı̆ını tespit etmişlerdir.

Döküm ve freze yöntemiyle elde edilen kuronlardaki veneer porselenlerinin kırılma dirençleri arasındaki farkın anlamlı olmadığı, DLMS grubundan farklarının ise anlamlı olduğu bu çalışmada tespit edilmiştir.

Papazoglou ve arkadaşları $^{49}$ optik mikroskop veya Scanning Electron Microscope (SEM) ile kırık yüzeylerinin değerlendirilmesi gerektiğini ifade etmişlerdir.

Araştırmamızda, döküm alt yapılarda \%50 oranında adeziv kopma, \%50 oranında kombine kopma, freze teknikle hazırlanan alt yapılarda, \%60 oranında adeziv kopma, \%40 oranında kombine kopma, DLMS tekniğiyle hazırlanan alt yapılarda ise \%55 oranında adeziv kopma, \%45 oranında kombine kopma şekli görülmüştür.

Sabit protezlerde diş preparasyonu ve alt yapıların anatomik şekilde hazırlanarak veneer porselenlerine yeterli destek sağlanması gerektiği çalışmada saptanmıştır.

\section{KAYNAKLAR}

1. Rosenstiel SF, Land M, Fujimoto J. Contemporary fixed prosthodontics. 3rd ed. St. Louis: Elsevier 2000:795-800.

2. Roberts $\mathrm{DH}$. The failure of retainers in bridge prostheses. An analysis of retainers. Brit Dent J 1970;128:117-24.

3. Llobell A, Nicholls JI, Kois JC, Daly CH. Fatigue life of porcelain repair systems. Int J Prosthodont

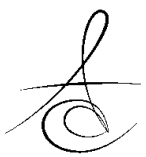


1992;5:205-13.

4. Bonfante EA, Coelho PG, Bayardo-Gonzalez DE, Thompson VP, Bonfante G. Effect of framework design on crown failure. Eur J Oral Sci 2009;1949.

5. Omori S, Komada W, Yoshida K, Miura H. Effect of thickness of zirconia-ceramic crown frameworks on strength and fracture pattern. Dent Mater J 2013;32: 189-94.

6. Akın E. Diş Hekimliğinde Porselen. $2^{\text {th }}$ ed. İstanbul, İstanbul Üniversitesi Basımevi. 1983:p.1-26.

7. Blatz MB, Sadan A, Kern M. Resin-ceramic bonding: a review of the literature. J Prosthet Dent 2003;89:268-74.

8. Craig RG. Restorative Properties in Restorative Dental Materials. New York: Mosby Publication, 2002: p.551-92.

9. Jones DW. Development of dental ceramics. An historical perspective. Dent Clin North Am 1985;29:621-44.

10. Anusavice K. In: Phillips' Science of Dental Materials. $11^{\text {th }}$ ed. Missouri, Saunders Publication 2003:p.655-719.

11. Claus $\mathrm{H}$. The structure and microstructure of dental porcelain in relationship to the firing conditions. Int J Prosthodont 1989; 2:376-84.

12. Leevailoj C, Platt JA, Cochran MA, Moore BK. Invitro study of fracture incidence and compressive fracture load of all-ceramic crowns cemented with resin-modified glass ionomer and other luting agents. J Prosthet Dent 1998;80:699-707.

13. Kelly JR. Clinically relevant approach to failure testing of all-ceramic restorations. J Prosthet Dent 1999;81:652-61.

14. Segal BS. Retrospective assessment of 546 allceramic anterior and posterior crowns in a general practice. J Prosthet Dent 2001;85:544-50.

15. Sailer I, Feher A, Filser F, Luthy $H$, Gauckler $D$, Scharer $\mathrm{P}$, Franz Hammerle $\mathrm{CH}$. Prospective clinical study of zirconia posterior fixed partial dentures: 3-year follow-up. Quintessence Int 2006;37:68593.

16. Kelly JR. Dental ceramics: current thinking and trends. Dent Clin North Am 2004;48:513-30.

17. Shillingburg $H$, Hobo $S$, Whitsett $L$, Jacobi $R$, Brackett $S$ Fundamentals of Fixed Prosthodontics. 3th ed. Chicago, Quintessence Publishing 1997:242-80.
18. Caputi S, Varvara G. Dimensional accuracy of resultant casts made by a monophase, one-step and two-step, and a novel two-step putty/lightbody impression technique: an in vitro study. J Prosthet Dent 2008;99:274-81.

19. Nissan J, Laufer BZ, Brosh T, Assif D. Accuracy of three polyvinyl siloxane puttywash impression techniques. J Prosthet Dent 2000;83:161-5.

20. Lawn BR, Pajares A, Zhang Y, Deng Y, Polack MA, Lloyd IK, Rekow ED, Thompson VP. Materials design in the performance of all-ceramic crowns. Biomaterials 2004;25:2885-92.

21. Sundh A, Sjogren G. A comparison of fracture strength of yttrium-oxide- partiallystabilized zirconia ceramic crowns with varying core thickness, shapes and veneer ceramics. J Oral Rehabil 2004;31:682-8.

22. Ambre MJ, Aschan F, Vult von Steyern P. Fracture strength of yttria-stabilized zirconium-dioxide $(Y-$ TZP) fixed dental prostheses (FDPs) with different abutment core thicknesses and connector dimensions. J Prosthodontics 2013; 22:377-82.

23. Tinschert J, Natt G, Mautsch W, Augthun M, Spiekermann $H$. Fracture resistance of lithium disilicate-, alumina-, and zirconia-based three-unit fixed partial dentures: a laboratory study. Int J Prosthodont 2001;14:231-8.

24. Filser $F$, Luthy $H$, Kocher $P$, Scharer $P, D$. G. Posterior all-ceramic bridgework. Quintessence of Dental Technology, 2003;1:28-41.

25. Cho L, Choi J, Yi YJ, Park CJ. Effect of finish line variants on marginal accuracy and fracture strength of ceramic optimized polymer/fiberreinforced composite crowns. J Prosthetic Dent 2004;91:554-60.

26. Piwowarczyk $A$, Lauer $H C$, Sorensen JA. In vitro shear bond strength of cementing agents to fixed prosthodontic restorative materials. J Prosthet Dent 2004;92:265-73.

27. Fabianelli A, Goracci C, Bertelli E, Monticelli F, Grandini S, Ferrari M. In vitro evaluation of wall-towall adaptation of a self-adhesive resin cement used for luting gold and ceramic inlays. J Adhes Dent 2005;7:33-40.

28. Zaimoğlu A, Can G. Sabit Protezler. 1th ed. Ankara, Ankara Üniversitesi Baskı, 2004:90-105.

29. Bagby M, Marshall S, Marshall Jr G. Metal ceramic

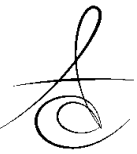


compatibility: a review of the literature. J Prosthet Dent 1990;63:21-5.

30. Smith TB, Kelly JR, Tesk JA. In vitro fracture behavior of ceramic and metal ceramic restorations. J Prosthodontics 1994;3:138-44.

31. Burke FJ, Fleming GJ, Nathanson D, Marquis PM. Are adhesive Technologies needed to support ceramics? An assessment of the current evidence. J Adhesive Dent 2002;4:7-22.

32. Zan T. Çeşitli Yüzey Şartlandırma İşlemlerinin Konvansiyonel Dental Porselenlerin Eğilme Dayanıklıl̆ı Üzerine Etkisi. Sağlık Bilimleri Enstitüsü, Hacettepe Üniversitesi Diş Hekimliği Fakültesi, Protetik Diş Tedavisi Anabilim Dalı, Ankara, 1999.

33. Ban S, Anusavice KJ. Influence of test method on failure stress of brittle dental materials. J Dent Res 1990;69:1791-9.

34. Baker PS, Clark AE, Jr. Compositional influence on the strength of dental porcelain. Int J Prosthodont 1993;6:291-7.

35. Beuer F, Aggstaller H, Edelhoff D, Gernet W. Effect of preparation design on the fracture resistance of zirconia crown copings. Dent Mater J 2008;27:3627.

36. Jalalian E, Atashkar B, Rostami R. The effect of preparation design on the fracture resistance of zirconia crown copings (computer associated design/computer associated machine, CAD/CAM system). J Dent 2011;8:123-9.

37. Malament KA, Socransky SS. Survival of Dicor glass-ceramic dental restorations over 14 years. Part II: effect of thickness of Dicor material and design of tooth preparation. J Prosthet Dent 1999;81:662-7.

38. Filser $F$, Luthy $H$, Kocher $P$, Scharer $P, L$. G. Posterior all-ceramic bridgework. Quintessence of Dental Technology 2003;1:28-41.

39. Aboushelib MN, Feilzer AJ, Kleverlaan CJ. Bridging the gap between clinical failure and laboratory fracture strength tests using a fractographic approach. Dent Mater 2009;25:383-91.

40. Otto T, De Nisco S. Computer-aided direct ceramic restorations: a 10-year prospective clinical study of Cerec CAD/CAM inlays and onlays. Int J Prosthodontics 2002; 15:122-8.

41. Rosentritt M, Steiger D, Behr M, Handel G, Kolbeck C. Influence of substructure design and spacer settings on the in vitro performance of molar zirconia crowns. J Dent 2009;37:978-83.

42. Molin MK, Karlsson SL. Five-year clinical prospective evaluation of zirconiabased

Denzir 3-unit FPDs. Int J Prosthodont 2008;21:223-7.

43. Forsh WY, Graig RG. Distrubution of stresses in porcelain fused to metal and porcelain jacket crowns. J Dent Res 1975;5:255.

44. Ortorp A, Jönsson D, Mouhsen A, Von Steyren PV (2011). The fit of cobalt-chromium three unit fixed dental prostheses fabricated with four different techniques: A comparative in vitro study. Dent Mater 27:356-63.

45. Takahashi T, Gunne J. Fit of implant frameworks: An in-vitro comparison between two fabrication technique. J Prosthet Dent 2003;89: 256-60.

46. Mörmann WH, Bindl A. All ceramic, chair-side computer-aided design/computer-aided machining restorations. Dent Clin North Am 2002; 46: 40526.

47. Akova T, Ucar Y, Tukay A, Balkaya MC, Brantley WA. Comparison of the bond strength of lasersintered and cast base metal dental alloys to porcelain. Dent Mater 2008;24:1400-4.

48. Suleiman $\mathrm{SH}$, Vult von Steyern P. Fracture strength of porcelain fused to metal crowns made of cast, milled or laser-sintered cobalt-chromium. Acta Odontologica Scand 2013;5:1280-1289.

49. Papazoglou E, Brantley WA, Carr AB, Johnston WM. Porcelain adherence to high-palladium alloys. J Prosthet Dent 1993;70: 386-94.

\section{Yazışma Adresi}

Prof. Dr. Zeynep YEŞİL DUYMUŞ

Recep Tayyip Erdoğan Üniversitesi

Diş Hekimliği Fakültesi

Protetik Diş Tedavisi Ana Bilim Dalı, Rize

Tel: 0464-2220001

E Mail: zyesilz@hotmail.com 